\title{
Catalysing the way towards antimicrobial effectiveness: A systematic analysis and a new online resource for antimicrobial-enzyme combinations against Pseudomonas aeruginosa and Staphylococcus
}

\section{aureus}

\author{
Paula Jorge*, Diana Alves, Maria Olívia Pereira \\ CEB - Centre of Biological Engineering, LIBRO - Laboratory of Research in Biofilms Rosário Oliveira, University of Minho, Campus de Gualtar, \\ 4710-057 Braga, Portugal
}

\section{A R T I C L E I N F O}

\section{Article history:}

Received 31 October 2018

Accepted 6 January 2019

Editor: Dr Seydina Diene

\section{Keywords:}

Antimicrobial combinations

Enzymes

Pseudomonas aeruginosa

Staphylococcus aureus

Database

\begin{abstract}
A B S T R A C T
Growing antimicrobial resistance and the resilience of biofilm infections have led researchers to study the potential of antimicrobial combinations, including those incorporating enzymes with biofilm-disrupting abilities. This work aimed to evaluate the journey of antimicrobial-enzyme combination research and to gain insights into its current status and most promising leads. Expert curators annotated and analysed all published experimental data on enzyme-containing combinations for two major biofilm-forming pathogens, namely Pseudomonas aeruginosa and Staphylococcus aureus. This entailed the construction of the first publicly accessible online database on antimicrobial-enzyme combinations, the Antimicrobial Enzyme Combinations Database (https://www.ceb.uminho.pt/aecd). Gathered data were also reconstructed as knowledge networks to help analyse and visualise annotated entities (e.g. enzymes, methods, strains, combination outputs). The database currently holds 122 and 206 annotated combinations for $P$. aeruginosa and $S$. aureus, respectively, and their analysis allowed a systematic review of the available evidence on enzyme combinations, reliably illustrating the studies being performed. The most tested enzymes (e.g. lysozyme, DNase, lysostaphin) were scrutinised and the rationale behind each combination was explained. This research area is still growing although current research gaps/opportunities were identified, such as lack of biofilm testing and studies on polymicrobial scenarios. Hopefully, this work will shed light on the synergistic potential of enzyme combinations and alleviate some of the time- and resource-consuming tasks related to enzyme combination research by helping the selection and design of new enzyme-related therapeutic options for $P$. aeruginosa and $S$. aureus infections.
\end{abstract}

(c) 2019 Elsevier B.V. and International Society of Chemotherapy. All rights reserved.

\section{Introduction}

The growing number of nosocomial infections associated with the emergence of antimicrobial-resistant micro-organisms has been recognised as a major concern affecting modern health care [1]. This problem becomes worse when micro-organisms switch from a planktonic to a sessile lifestyle and live as biofilms, microconsortia of surface-adhering cells enclosed in a self-produced matrix of extracellular polymeric substances such as polysaccharides, proteins and extracellular DNA (eDNA) [2]. Once established, biofilms are less susceptible to antimicrobial treatment and the host immune system than their planktonic counterparts, making biofilm-related nosocomial infections a burden to public health systems [3].

\footnotetext{
* Corresponding author. Tel.: +351 253601 968; fax: +351 253604429 .

E-mail address: paulajorge@ceb.uminho.pt (P. Jorge).
}

To prevent or treat bacterial infections, a wide range of antibiotics have been extensively used in clinical practice. However, their overuse, inappropriate selection, dosing and inadequate duration of application may be at the root of microbial resistance development [4]. Great efforts have been directed to overcome these problems, namely the use of alternative natural compounds such as enzymes [5] as well as the design of synergistic antimicrobial combinations [6].

One of the many promising strategies involving enzymes is their use to disturb biofilm formation by targeting the compounds involved in bacterial adhesion or the polymers in the biofilm matrix. For example, given the role of proteins and glycoproteins in the adhesion of many fouling organisms, proteases are the most tested and successful enzymes used in the control of marine biofouling [7]. Proteolytic enzymes, such as lysostaphin, proteinase $\mathrm{K}$, trypsin and serratiopeptidase, have been investigated in the fight against biofilm infections [8-10]. For example, in the clinical 
context, lysostaphin has been the subject of great interest to fight methicillin-resistant Staphylococcus aureus (MRSA) because of its ability to cleave the cross-linking pentaglycine bridges of the cell wall of these bacteria [11]. Polysaccharide-degrading enzymes, such as lysozyme, alginate lyase and dispersin B, are also widely explored. Lysozyme can damage the bacterial cell wall by catalysing the hydrolysis of peptidoglycan [12], whilst alginate lyase is able to degrade the matrix-constituting polysaccharide alginate [13]. Another well-studied matrix-disruptive enzyme is dispersin B, a glycoside hydrolase able to degrade poly- $N$ acetylglucosamine (PNAG), an important matrix polysaccharide $[14,15]$. eDNA is another important matrix component, which makes the enzyme DNase I a promising alternative to inhibit, disperse or even increase biofilm susceptibility to antimicrobials. In fact, this enzyme has already been used in the therapy of patients suffering from cystic fibrosis [16].

Another enzyme-based strategy that is currently being explored to control biofilms includes the use of enzymes that degrade quorum-sensing (QS) signal molecules. QS is a bacterial cell-cell communication process that regulates many physiological activities, including the expression of virulence factors and biofilm formation [17]. The use of enzymes able to inhibit bacterial QS systems therefore holds great potential as an antimicrobial therapy. $\mathrm{N}$-acyl-homoserine lactones (AHLs) are one of the most identified signal molecules produced by Gram-negative bacteria. Enzymes able to degrade these molecules will thus compromise or even abolish QS-regulated functions [18].

A different and indirect enzymatic strategy to control biofilms relies on the use of enzymes to produce biocides that actively interfere with bacterial attachment. Enzymes commonly used in this strategy include glucose oxidase, hexose oxidase [19] and haloperoxidases [20]. Oxidases are used because they produce hydrogen peroxide, whilst haloperoxidase catalyses the formation of hypohalogenic acid, both with potential cytotoxic effects [21].

Nevertheless, the use of enzymes, especially those whose unique target is the biofilm matrix, can fall short in eradicating infections if the dispersed bacteria originating from the disrupted biofilm remain viable and are able to colonise another area. Therefore, the combination of enzymes with antimicrobials can both effectively disperse the biofilm and kill the biofilm-forming bacteria. Antimicrobial combinations, such as enzyme-antimicrobial combinations, are currently one of the major antimicrobial research lines as they hold several advantages over single antimicrobial use, such as an increase in the antimicrobial spectrum, prevention of resistance, a reduction in toxicity and side effects, and the attainment of synergistic activity [22].

Given the existing panoply of enzyme-based antimicrobial and antibiofilm approaches, the main aim of this work was to curate and analyse experimental data on enzyme-incorporating combinations tested against Pseudomonas aeruginosa and S. aureus, aiming to highlight the most relevant enzyme combination strategies for each micro-organism, mainly in biofilm and in vivo scenarios. To complete this, the first publicly accessible online database on antimicrobial-enzyme combinations was constructed, in which all data are deposited and available in an organised and searchable fashion. In addition, all data were reconstructed as species-specific knowledge networks, which aided data structuring and analysis by allowing a condensed and organised visualisation of this high volume of data.

\section{Materials and methods}

\subsection{Information retrieval}

To extract information from the scientific literature regarding antimicrobial combination studies with enzymes targeting $P$. aerug- inosa and S. aureus, an in-house dictionary of relevant enzymes for these bacteria was built based on the expertise at that time. Next, the scope of the PubMed queries was narrowed to experiments mentioning at least one of these enzymes, the name of the bacteria, and any term variants denoting common agent combinations (e.g. synergy, antagonism, chequerboard). Although most queries were constructed to be as specific as possible, e.g. (Staphylococcus aureus OR S. aureus OR MRSA OR MSSA OR aureus) AND (lysin OR endolysin OR 'murein hydrolase') AND (synerg* OR antagon* OR additive* OR indifferen* OR FIC OR FICI OR checkerboard OR time+kill), the authors chose to also use less specific queries, e.g. (Pseudomonas aeruginosa OR P. aeruginosa) AND enzyme* AND (combined OR combination) AND (biofilm OR matrix), to guarantee that all enzymes and therefore all relevant documents were included in the analysis. All enzymes used in the queries are listed in Supplementary Table S1.

Next, the relevance of each retrieved document was assessed, i.e. papers describing experimental testing of enzymes combined with other agents against one of the bacteria of interest were marked as relevant. This was followed by the annotation of relevant information, namely entities of interest (e.g. enzymes, drugs), combination outcome (e.g. synergism, antagonism), organisms (P. aeruginosa and S. aureus), strains (e.g. PAO1, ATCC 25923), mode of growth (e.g. biofilm, planktonic) and experimental methods [e.g. minimum inhibitory concentration (MIC), colony-forming units (CFU)], on the full-text documents.

\subsection{Data organisation and presentation}

The annotated combinations were categorised as 'synergy', 'additiveness', 'indifference' and 'antagonism'. Other categories, named 'synergy/additiveness', 'additiveness/indifference' and 'antagonism/indifference', were also used to denote non-conclusive results. This categorisation was performed as in past works [23,24]. Briefly, annotation of the combination category was primarily based on the textual descriptions presented in the papers; however, two main standard definitions were used to assess the combination category for those studies where harmonisation of the drawn conclusions was needed, namely those recommended for in vitro testing through chequerboard assay and time-kill curves [22,25]. All entities of interest were classified as either 'drugs', 'antimicrobial peptides' (AMPs), 'enzymes' or 'other', resorting to the consultation of specialised databases, namely DrugBank (https://www.drugbank.ca/), the Antimicrobial Peptide Database (http://aps.unmc.edu/AP/main.php) and KEGG Enzyme Database (https://www.genome.jp/kegg/annotation/enzyme.html). All data were reconstructed as networks and were analysed using $\mathrm{Cy}$ toscape and Excel. All of the annotated data were made publicly available in our newly constructed Antimicrobial Enzyme Combinations Database (AECD) (https://www.ceb.uminho.pt/aecd), the first ever antimicrobial-enzyme combinations database. All data were transformed into JSON format and the online database was constructed using Visual Studio software and HTML, CSS, JavaScript and jQuery programming languages.

\section{Results and discussion}

\subsection{Database overview}

The curated information on experimentally tested combinations of enzymes with other agents towards $P$. aeruginosa and $S$. aureus is publicly accessible at a database constructed for this effect, the AECD. Currently, the AECD contains a total of 122 and 206 combinations, correspondingly retrieved from 54 and 71 articles studying $P$. aeruginosa and $S$. aureus, respectively, but its content is dynamic and updatable so that it can include more combinations and 

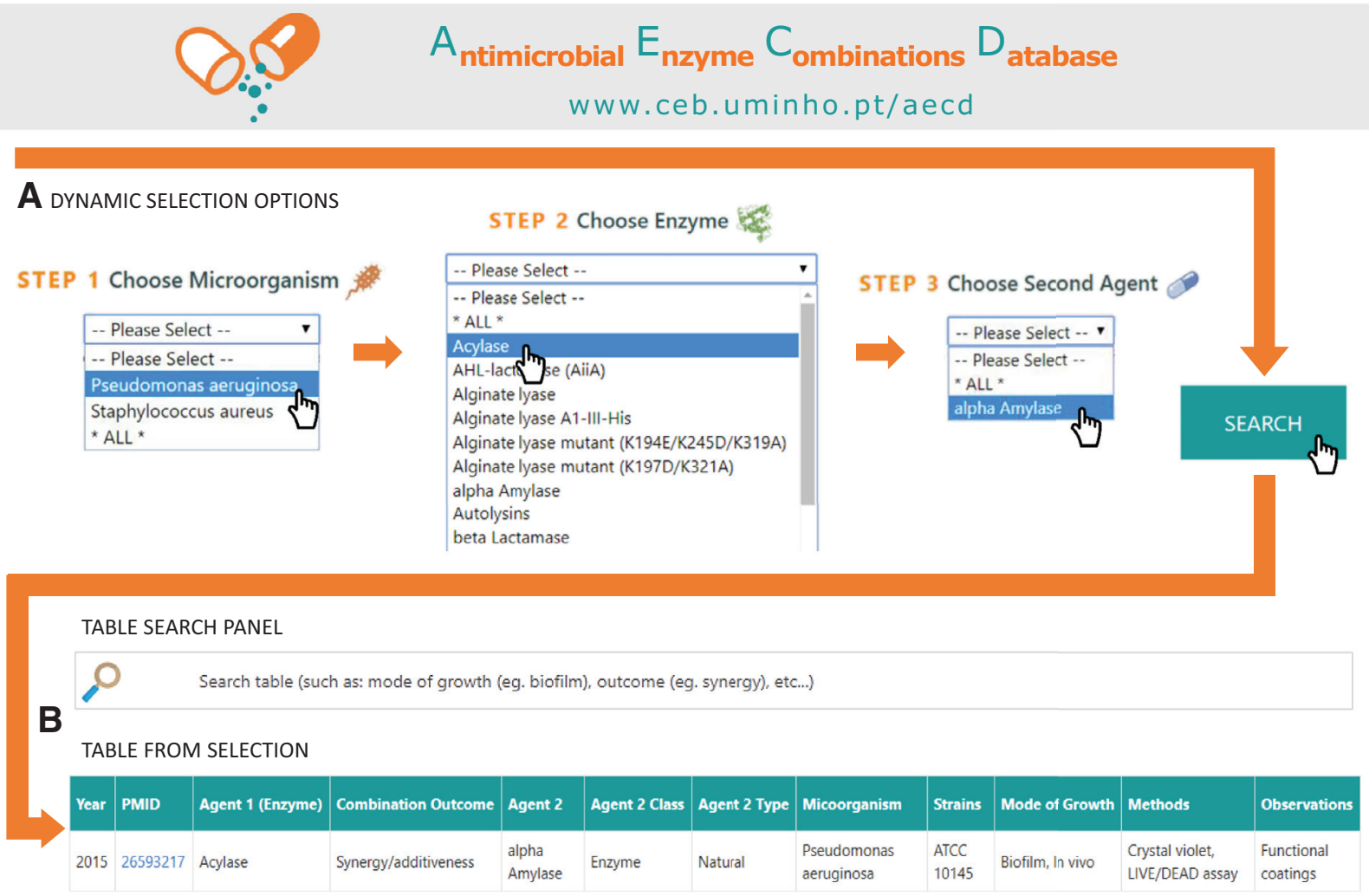

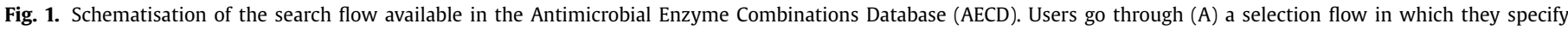

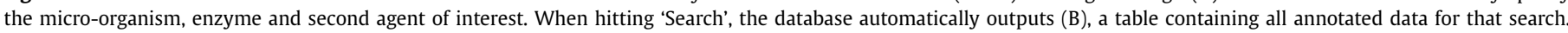

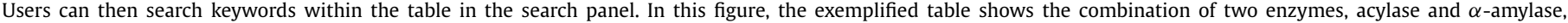
tested on Pseudomonas aeruginosa.

micro-organisms in the near future. Database users are allowed to do more or less defined searches depending on their specific interests. Specifically, users are presented with a unidirectional flow of three different selection options, where they can specify (or not, for which they can choose the option 'all') their micro-organism, enzyme and combined agent of interest (Fig. 1A). After selection, a table containing all the annotated data on the specified combination(s) is automatically generated (Fig. 1B), with information ranging from the specified enzymes, second agents and microorganisms to strains, methods, modes of growth, among other curated data. Users can then search within the generated table for keywords of interest (e.g. biofilm, synergy), further restricting their search this way (Fig. 1B). As a bonus, the database also provides more information content, such as the current database statistics and a brief explanation on the importance of enzyme combination studies.

To annotate all of the information presented in this work, a significant curation effort was made, including the analysis of a total of 488 and 472 documents for P. aeruginosa and S. aureus, respectively, with $11-15 \%$ classified as relevant for the annotation of enzyme combination information (Table 1 ). This low relevance rate is the result of the lack of standardisation in terms of abstract construction and of the absence of ontologies, i.e. formal designations and definitions, within the particular domain of antimicrobial combinations and/or enzyme research. In addition, the use of a few, yet less specific, queries, as stated in Section 2.1 contributed to these percentages. This analysis shows that efforts are required to ameliorate both writing, which should comprise the development of an ontology, and presentation of scientific publications, aiming at a common standard within a given field of study so that the time-consuming task of scientific bibliome analysis is cut down to a minimum.

When analysing the retrieved documents, it was interesting to observe that the number of documents regarding enzyme combinations has risen in the last years (Supplementary Fig. S1), indicating an increasing interest in the study of antimicrobial combinations using enzymes. This is probably linked to the escalating antimicrobial resistance that has been reported in the past years, which antimicrobial combinations may help prevent and overcome [6].

In terms of the secondary agents, i.e. the compounds combined with the enzymes, almost one-half of them were classified as drugs, followed by AMPs, other compounds and enzymes, in descending order (Supplementary Fig. S2). Most tested drugs are antibiotics currently used in clinical practice, such as ciprofloxacin and tobramycin for $P$. aeruginosa, and vancomycin and oxacillin for $S$. aureus. This observation indicates a propensity for these combination studies to attempt to improve the effectiveness of known compounds and possibly overcome resistance phenomena by combining them with enzymes. Indeed, this antibiotic repurposing strategy is a current research approach that evolved as a response to the reduction in investment into finding new antimicrobials, being a cost-effective way to improve the efficacy of already clinically approved drugs [26].

In terms of the methodology used to evaluate the effectiveness of the combinations in the analysed studies, it was interesting to observe that most did not exploit standard antimicrobial combination tests, such as the time-kill assay, chequerboard assay or Etest [22]. In fact, time-kill assays were used in only 2.7\% and 5.0\% of cases for $P$. aeruginosa and $S$. aureus, respectively. In turn, the 
Table 1

Overview of the annotated data on enzyme combinations against Pseudomonas aeruginosa and Staphylococcus aureus.

\begin{tabular}{|c|c|c|c|c|c|c|c|}
\hline Organism & $\begin{array}{l}\text { No. of } \\
\text { relevant } \\
\text { documents }\end{array}$ & $\begin{array}{l}\text { No. of } \\
\text { annotated } \\
\text { combinations }\end{array}$ & $\begin{array}{l}\text { Top three } \\
\text { enzymes }\end{array}$ & $\begin{array}{l}\text { Top three } \\
\text { non-enzyme agents }{ }^{\mathrm{b}}\end{array}$ & $\begin{array}{l}\text { Combination } \\
\text { category }^{\mathrm{c}, \mathrm{d}}\end{array}$ & Top three methods ${ }^{b}$ & $\begin{array}{l}\text { Top three modes } \\
\text { of growth }\end{array}$ \\
\hline \multirow[t]{4}{*}{ P. aeruginosa } & $54(11 \%)$ & 122 & Lysozyme (24\%) & Tobramycin (8.1\%) & Synergy (48\%) & $\begin{array}{l}\text { Cell viability (CFU) } \\
(30 \%)\end{array}$ & Planktonic (51\%) \\
\hline & & & DNase (19\%) & Ciprofloxacin (5.8\%) & Additiveness (11\%) & $\begin{array}{l}\text { Crystal violet assay } \\
(8.2 \%)\end{array}$ & Biofilm (36\%) \\
\hline & & & $\begin{array}{l}\text { Alginate lyase } \\
(13 \%)\end{array}$ & $\begin{array}{l}\text { LL-37, EDTA ( } 4.7 \% \\
\text { each) }\end{array}$ & Indifference (29\%) & MIC (6.7\%) & In vivo $(6.6 \%)$ \\
\hline & & & & & Antagonism (12\%) & & \\
\hline \multirow[t]{4}{*}{ S. aureus } & $71(15 \%)$ & 206 & Lysozyme (19\%) & Vancomycin (6.5\%) & Synergy (50\%) & $\begin{array}{l}\text { Cell viability (CFU) } \\
(27 \%)\end{array}$ & Biofilm (21\%) \\
\hline & & & $\begin{array}{l}\text { Lysostaphin, } \\
\text { endolysin ( } 15 \% \\
\text { each) }\end{array}$ & Gentamicin (3.0\%) & Additiveness (9.2\%) & $\begin{array}{l}\text { Chequerboard assay } \\
(18 \%)\end{array}$ & In vivo $(8.8 \%)$ \\
\hline & & & & Oxacillin $(2.4 \%)$ & Indifference (22\%) & $\begin{array}{l}\text { Bacterial growth } \\
\text { (OD) (10\%) }\end{array}$ & Biofilm (21\%) \\
\hline & & & & & Antagonism (18\%) & & \\
\hline
\end{tabular}

\footnotetext{
CFU, colony-forming units; MIC, minimum inhibitory concentration; OD, optical density.

a $\%$ is relative to the total number of analysed documents.

b $\%$ is relative to the total sum of the respective non-repeated entities per PMID.

c $\%$ is relative to the total number of annotated combinations.

d The combination categories 'synergy/additiveness' and 'additiveness/indifference' were included in the categories 'synergy' and 'additiveness', respectively, for calculation purposes.
}

chequerboard assay was present in only $2.7 \%$ and $18 \%$ of the tested combinations for the same bacteria, with no Etests being used in any of the analysed studies. This non-standard use of antimicrobial combination methodologies, and subsequent different outcome interpretations throughout the analysed studies, raises concerns regarding the validity and comparativeness of the drawn conclusions. As they lack specific combination interpretation rules and thresholds, non-standard tests for enzyme-antimicrobial combinations (e.g. MIC, microscopy analysis) need to be carefully used, especially in what is related to data analysis and combination outcome interpretation in order to guarantee conclusion validity and comparability.

As stated, biofilms are known to be the mode of growth of ca. $80 \%$ of human bacterial infections [27] and their eradication can require up to a thousand times greater antibiotics than their planktonic counterparts [28]. Despite this, most of the analysed studies tested enzyme combinations on planktonic bacteria, with only $21-36 \%$ using biofilms as the mode of bacterial growth (Table 2). Although planktonic testing is practical and informative, studies should entail a higher level of biofilm testing in order to better mimic a real-life infection scenario. Following biofilms, in vivo testing was the least used bacterial growth scenario, representing $6.6-8.8 \%$ of the annotated combinations. Although in vivo biofilm testing is generally recommended, since these biofilms can greatly differ from in vitro biofilms owing to complex pathogenhost interactions, most studies do not use this approach, probably as a result of the various ethical and practical issues (e.g. costs, feasibility) that arise with animal experimentation [29].

\subsection{Enzyme combinations targeting Pseudomonas aeruginosa}

The most annotated enzyme for $P$. aeruginosa, both generally and in in vivo scenarios, was lysozyme, as best represented in the networks depicted in Fig. $2 \mathrm{~A}$ and $2 \mathrm{C}$. This enzyme exerts its antibacterial function by catalysing the breakdown of the bacterial cell wall through hydrolysis of the 1,4- $\beta$-linkage between the monosaccharides $N$-acetyl-muramic acid (NAM) and $N$-acetylD-glucosamine (NAG) that comprise peptidoglycan, and through a non-enzymatic mode of action that consists of the induction of pore formation in the bacterial membrane. This conserved antimi- crobial protein is ubiquitous to the animal kingdom, being a major player in the innate immune system and inflammatory response [30]. In mammals, this enzyme is found in blood, secretions such as tears, urine, saliva and milk, mucosal surfaces and phagocytes [30]. These traits properly justify why lysozyme was one of the most combined enzymes (Table 2), especially in vivo, and why most studies consistently used this enzyme throughout the years (Supplementary Fig. S1). Most likely, its ubiquity in the host makes it less likely for any toxic or secondary effects to appear, and its inflammation-modulating ability greatly helps in infection eradication and resolution. In vivo, lysozyme was mainly tested on models of $P$. aeruginosa lung infection combined with tobramycin (8.3\%), which is a well-known antibiotic used to treat Gram-negative infections, namely those caused by this bacterium. The mechanism of action of tobramycin is mostly at the intracellular level and consists of disrupting protein synthesis [31]. Its action can be thus facilitated if the bacterial membrane barrier is compromised, justifying its combination with lysozyme. Sadly, so far no synergistic outcomes were observed between the two agents in vivo.

Other enzymes combined in vivo against $P$. aeruginosa include DNase, $\alpha$-amylase, and acylase (Table 2). $\alpha$-Amylase catalyses the hydrolysis of polysaccharides such as starch, glycogen and others [32], including those present in the biofilm matrix [33,34]. On the other hand, acylase is involved in the hydrolysis of $\mathrm{N}$-acylated amino acids by removing the acyl side chain [35], with similar activity as AHLs, thus targeting QS [34]. Interestingly, amylase and acylase were combined with each other, which proved to be a promising strategy since their combination resulted in a positive (synergy/additiveness) outcome against $P$. aeruginosa in vivo infection scenarios, as well represented in the network depicted in Fig. 2C.

Regarding $P$. aeruginosa biofilm scenarios, DNase was the most combined enzyme, followed by alginate lyase (Table 2). It is well known that the matrix is a critical constituent of biofilms as it provides mechanical stability, mediating bacterial adhesion to surfaces and making a consistent, three-dimensional polymer network that interconnects and transiently immobilises biofilm cells [2]. Alginate is a matrix polysaccharide that contributes to the mucoid structure of $P$. aeruginosa biofilms and plays a role in bacterial virulence and persistence in lung infections, making this polymer an important target in medical research [13]. eDNA, on the other 
Table 2

Overview of the annotated data on enzyme combinations tested against Pseudomonas aeruginosa and Staphylococcus aureus biofilms and in vivo scenarios.

\begin{tabular}{|c|c|c|c|c|c|c|c|}
\hline $\begin{array}{l}\text { Mode of } \\
\text { bacterial } \\
\text { growth }\end{array}$ & Species & $\begin{array}{l}\text { No. of } \\
\text { relevant } \\
\text { documents }\end{array}$ & $\begin{array}{l}\text { No. of com- } \\
\text { binations }\end{array}$ & $\begin{array}{l}\text { Combination } \\
\text { outcomes }^{\mathrm{a}}\end{array}$ & Top three enzymes & Top three non-enzyme agents & Top three methods \\
\hline \multirow{2}{*}{ Biofilm } & P. aeruginosa & 22 & 34 & $\begin{array}{l}\text { Synergy (70\%) } \\
\text { Indifference (17\%) } \\
\text { Additiveness (5.6\%) } \\
\text { Antagonism }(8.3 \%)\end{array}$ & $\begin{array}{l}\text { DNase }(29 \%) \\
\text { Alginate lyase (14\%) } \\
\text { Glycosyl hydrolase PslG } \\
(7.1 \%)\end{array}$ & $\begin{array}{l}\text { Ciprofloxacin (15\%) } \\
\text { Tobramycin (11\%) } \\
\text { Piperacillin/tazobactam (7.4\%) }\end{array}$ & $\begin{array}{l}\text { Cell viability (CFU) (29\%) } \\
\text { Crystal violet assay (21\%) } \\
\text { LIVE/DEAD assay }(8.8 \%)\end{array}$ \\
\hline & S. aureus & 17 & 39 & $\begin{array}{l}\text { Synergy (79\%) } \\
\text { Indifference (15\%) } \\
\text { Additiveness (5.1\%) } \\
\text { Antagonism (0\%) }\end{array}$ & $\begin{array}{l}\text { Dispersin B (19\%) } \\
\text { Lysostaphin (12\%) } \\
\text { DNase, amylase, endolysins, } \\
\text { proteinase K, } \\
\text { serratiopeptidase ( } 7.7 \% \text { each) }\end{array}$ & $\begin{array}{l}\text { Vancomycin, oxacillin }(12 \% \\
\text { each) } \\
\text { Linezolid }(8.0 \%)\end{array}$ & $\begin{array}{l}\text { Cell viability (CFU) (35\%) } \\
\text { Crystal violet assay (23\%) } \\
\text { CLSM (12\%) }\end{array}$ \\
\hline \multirow{2}{*}{ In vivo } & P. aeruginosa & 4 & 7 & $\begin{array}{l}\text { Synergy (29\%) } \\
\text { Additiveness (57\%) } \\
\text { Antagonism (14\%) } \\
\text { Indifference }(0 \%)\end{array}$ & $\begin{array}{l}\text { Lysozyme ( } 33 \%) \\
\text { Amylase, DNase, acylase, } \\
\text { lysozyme variant 2-3-7 (17\% } \\
\text { each) }\end{array}$ & $\begin{array}{l}\text { Tobramycin }(50 \%) \\
\text { DNA, Tet009 (25\% each) }\end{array}$ & $\begin{array}{l}\text { Cell viability (CFU) (29\%) } \\
\text { Inflammatory index, } \\
\text { bacterial burden, } \\
\text { LIVE/DEAD assay, crystal } \\
\text { violet assay, fluorescence } \\
\text { microscopy ( } 14 \% \text { each) }\end{array}$ \\
\hline & S. aureus & 7 & 11 & $\begin{array}{l}\text { Synergy (73\%) } \\
\text { Indifference (27\%) } \\
\text { Additiveness, } \\
\text { antagonism (0\% each) }\end{array}$ & $\begin{array}{l}\text { Endolysins (50\%) } \\
\text { Lysostaphin (25\%) } \\
\text { Serratiopeptidase, dispersin } \\
\text { B (13\% each) }\end{array}$ & $\begin{array}{l}\text { Vancomycin (25\%) } \\
\text { Acticoat }^{\mathrm{TM}} \text {, daptomycin, } \\
\text { levofloxacin, nafcillin, oxacillin, } \\
\text { ranalexin ( } 13 \% \text { each) }\end{array}$ & $\begin{array}{l}\text { Cell viability (CFU) (75\%) } \\
\text { Survival rate }(25 \%) \\
\text { - }\end{array}$ \\
\hline
\end{tabular}

CFU, colony-forming units; CLSM, confocal laser scanning microscopy.

a Presented in descending order.

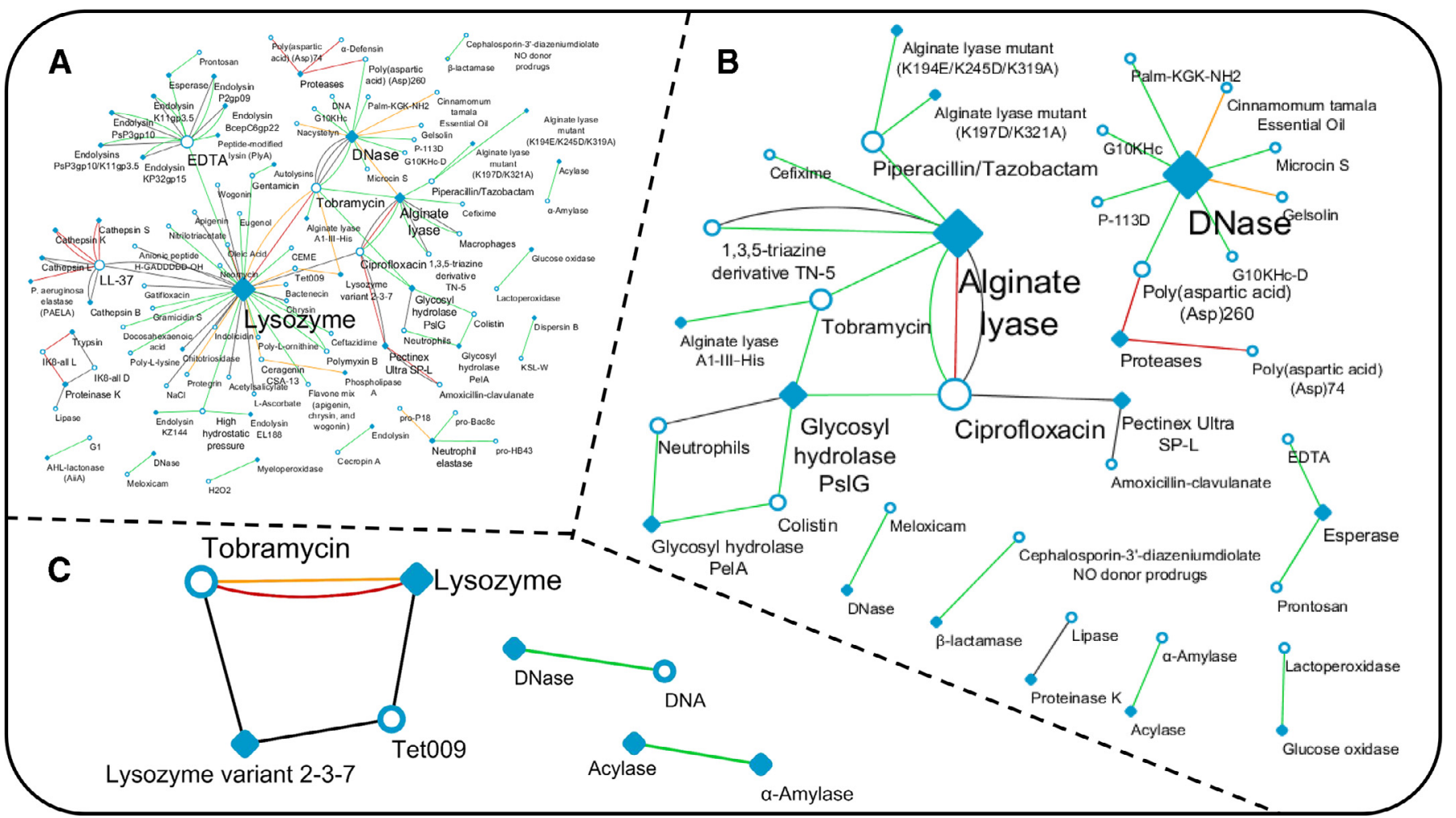

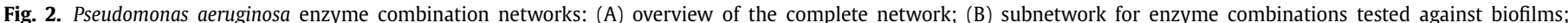

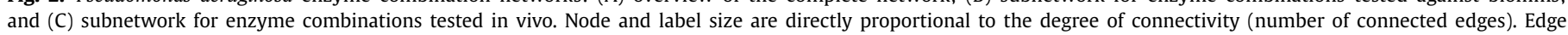

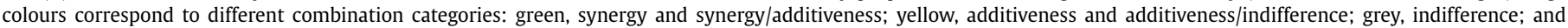
red, antagonism. Node shapes correspond to different type of agents: diamonds, enzymes; circles, non-enzyme agents.

hand, is important for biofilm structure since it is responsible for binding biopolymers in the matrix through attractive, short-range acid-base interactions [36]. Given the role of the substrates of both enzymes, most studies took advantage of their catalytic activities to dismantle the biofilm matrix and cause biofilm dispersal. Theoretically, this outcome makes bacterial cells more easily accessible to the action of the combined antimicrobial agent, which, in the case of these enzymes tested on biofilms, included mostly drugs (70\%) (e.g. ciprofloxacin, piperacillin/tazobactam) and AMPs (25\%) (e.g. G10KHc, microcin S) (Fig. 2B). Furthermore, most of these biofilm-targeting combinations were classified as synergistic $(75 \%)$ or additive (20\%) (Fig. $2 \mathrm{~B}$ ), demonstrating the potential for the use of these enzymes in combinatorial therapies against biofilm-related infections. 


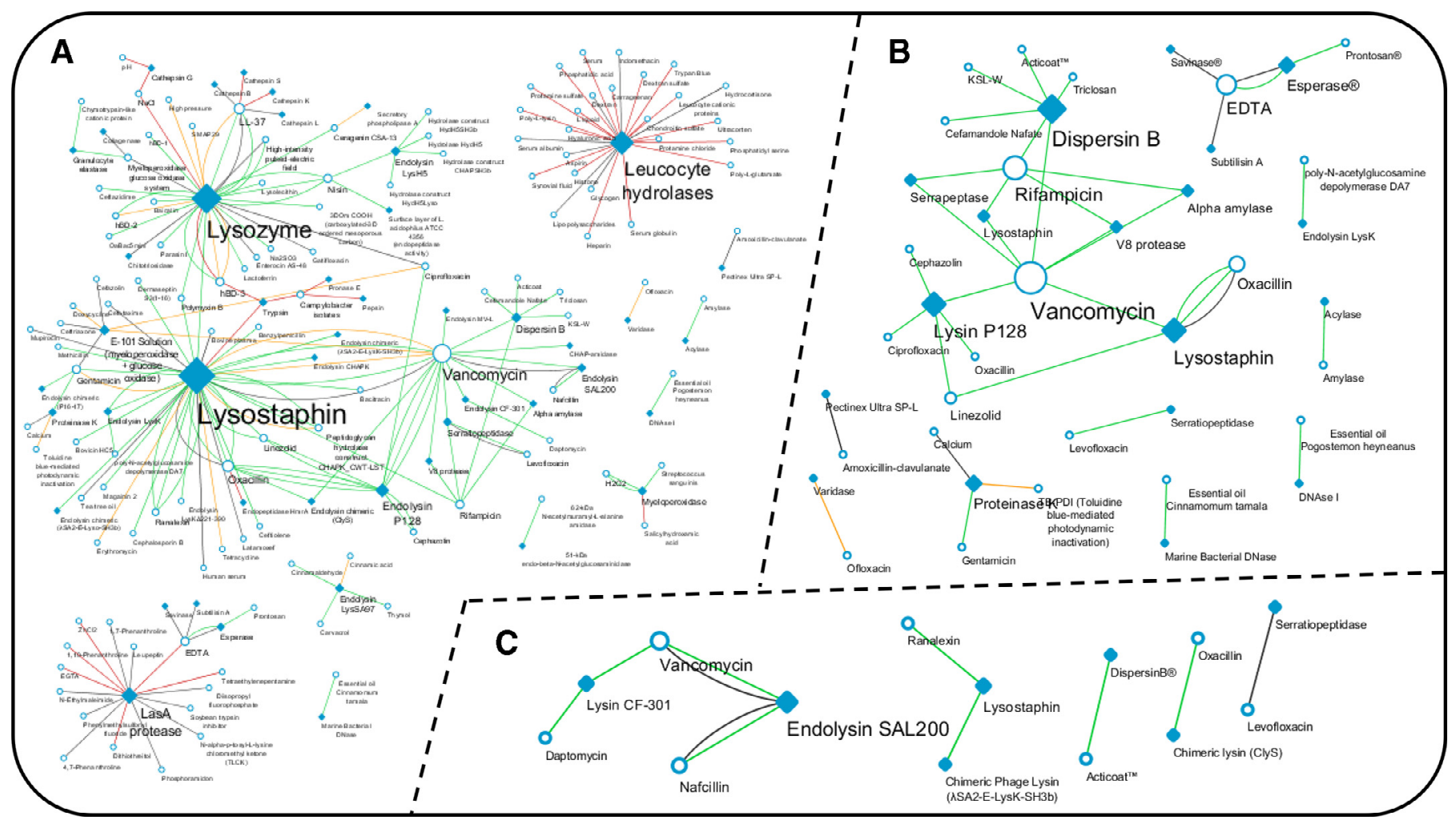

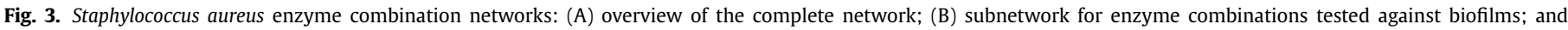

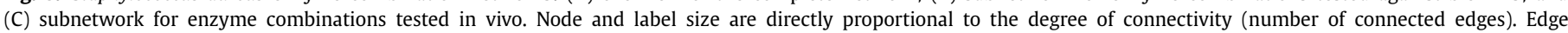

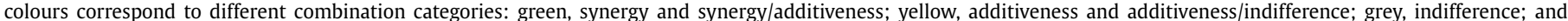
red, antagonism. Node shapes correspond to different type of agents: diamonds, enzymes; circles, non-enzyme agents.

In turn, the third most combined enzyme against $P$. aeruginosa biofilms was PslG (Table 2), a glycosyl hydrolase that is involved in the synthesis of the key biofilm matrix exopolysaccharide Psl [37], but with degrading activity towards Psl and probably other matrix exopolysaccharides when introduced exogenously or overexpressed, thus causing biofilm dispersal [38]. PslG was mainly combined with drugs (75\%) (ciprofloxacin and tobramycin), the AMP colistin (13\%) and neutrophils (13\%), with $75 \%$ of the outcomes being of synergy, as seen in the network shown in Fig. $2 \mathrm{~B}$.

\subsection{Enzyme combinations targeting Staphylococcus aureus}

Similarly to $P$. aeruginosa, lysozyme was the most tested enzyme against $S$. aureus (Table 1 ). However, contrary to what was observed for $P$. aeruginosa, lysozyme did not have a predominant role in combination testing against biofilms or in vivo scenarios for S. aureus (Table 2), being mostly tested on planktonic cultures, as shown in the networks depicted in Fig. 3.

Regarding biofilm scenarios, the most combined enzyme was dispersin B, a glycoside hydrolase produced by Actinobacillus actinomycetemcomitans with biofilm-dispersing ability through the degradation of PNAG, an important matrix polysaccharide necessary for biofilm formation $[14,15]$. Dispersin B was mainly combined with drugs $(67 \%)$ (e.g. rifampicin, triclosan), but also the AMP KSL-W (17\%) and the antimicrobial silver dressing Acticoat ${ }^{\mathrm{TM}}$ (17\%), with synergistic outcomes in all cases. The second most combined enzyme against $S$. aureus biofilms was lysostaphin (Table 2). This enzyme is a class III bacteriocin usually produced by another staphylococcal species, Staphylococcus simulans, that catalyses the hydrolysis between glycine residues constituting the peptidoglycan cross-bridges [39].
Overall, lysostaphin biofilm-targeting combinations solely included intracellularly acting antibiotics (oxacillin, linezolid and vancomycin) (Fig. 3B). The rationale behind the use of this enzyme is thus the same as for lysozyme. Other enzymes tested against $S$. aureus biofilms included amylase, proteinase $\mathrm{K}$, DNase, endolysins and serratiopeptidase (Table 2). Proteinase $K$ and serratiopeptidase are proteolytic enzymes able to cause biofilm dispersal by degrading proteins responsible for biofilm establishment (e.g. S. aureus surface proteins). Interestingly, however, serratiopeptidase has been reported to show proteolytic-independent antistaphylococcal activity [10]. Endolysins, in turn, are peptidoglycan hydrolases naturally produced by bacteriophages that are able to disrupt the bacterial membrane [40]. These five different enzymes were mainly combined with antibiotic drugs (69\%), such as rifampicin and vancomycin, achieving overall synergistic outcomes (88\%), as corroborated by the network in Fig. 3B.

In turn, endolysins were the most combined type of enzymes used in S. aureus in vivo testing (Table 2). Most endolysins demonstrate near species specificity, which is a great advantage since it avoids selective pressure on commensal populations [40], making them beneficial when tested in vivo. The fact that these enzymes and their combinations were overall preferably tested against $S$. aureus (15\%) (Table 1) rather than $P$. aeruginosa (4.8\%) is linked to the higher peptidoglycan accessibility in Gram-positive bacteria as it constitutes the outer part of the bacterial membrane, facilitating enzyme action. In vivo combinations using endolysins were overall synergistic (75\%) and involved mostly drugs (88\%) (e.g. nafcillin, vancomycin), as depicted in Fig. 3C. These positive outcomes, especially considering that most were obtained in MRSA in vivo scenarios, strengthen the value of using endolysin combinations to treat $S$. aureus-related infections. Alongside endolysins, lysostaphin 
was the second most tested enzyme, followed by the enzymes serratiopeptidase and dispersin B, whose relevance to these studies is mentioned above.

\section{Conclusions}

Analysis of the systematically annotated information presented in this work was able to paint a picture of the types of studies being performed regarding enzyme combinations towards $P$. aeruginosa and S. aureus infections. Some shortcomings in terms of experimental design and methodology were pointed out, such as the lack of biofilm and in vivo testing and the use of non-standard combination tests. This analysis was accompanied by the examination of the most tested enzymes and combined agents, including those used in biofilm and in vivo experimentation for each bacterial species. Annotated enzymes pertained to different types of functions, namely matrix-degrading enzymes (e.g. DNase, alginate lyase, dispersin B), cell wall hydrolases (e.g. lysozyme, lysostaphin) and QS inhibitors (e.g. acylase), demonstrating the multiplicity of antibiofilm and anti-infective potential that lays in this very diverse class of biomolecules.

At this point, and as perceived by the gathered data, enzyme combination research is still growing, with many showing promising results. For example, great potential to fight polymicrobial infections may be present in those enzymes that so far have only been effectively tested against both bacteria in single-species cultures but show synergistic combination outcomes in biofilm and in vivo settings, such as DNase and amylase. This would be clearly advantageous given the multispecies nature of most real-life infections. As the number of annotated enzymes tested against both species is still low, showing a current gap in this field of research, this can be regarded as an opportunity to catalyse enzyme combination studies towards biofilm-related infection treatment.

All of the gathered data are publicly available online in the AECD (https://www.ceb.uminho.pt/aecd) in a searchable format with the hope that they will help researchers to cut down both on the time and effort spent in the design of novel and promising enzyme combination therapies against $P$. aeruginosa and $S$. aureus infections. This database will undergo continuous updating in order to include new, experimentally validated enzyme combinations tested against not only $P$. aeruginosa and $S$. aureus but also other new and relevant pathogens.

\section{Funding}

This work was supported by the Portuguese Foundation for Science and Technology (FCT) under the scope of the strategic funding of UID/BIO/04469 unit and COMPETE 2020 [POCI-010145-FEDER-006684] and BioTecNorte operation [NORTE-01-0145FEDER-000004], funded by the European Regional Development Fund under the scope of Norte2020 - Programa Operacional Regional do Norte. The authors also recognise COMPETE2020 and FCT for the project POCI-01-0145-FEDER-029841.

\section{Competing interests}

None declared.

\section{Ethical approval}

Not required.

\section{Acknowledgments}

The authors acknowledge Prof. Anália Lourenço, Martín PérezPérez and Gael Pérez Rodríguez (University of Vigo, Vigo, Spain) for help in the assessment of document relevance and initial annotation of relevant entities.

\section{Supplementary materials}

Supplementary material associated with this article can be found, in the online version, at doi:10.1016/j.ijantimicag.2019.01. 001.

\section{References}

[1] Lax S, Gilbert JA. Hospital-associated microbiota and implications for nosocomial infections. Trends Mol Med 2015;21:427-32. doi:10.1016/j.molmed.2015. 03.005.

[2] Flemming H-C, Wingender J. The biofilm matrix. Nat Rev Microbiol 2010;8:623-33. doi:10.1038/nrmicro2415.

[3] Miquel S, Lagrafeuille R, Souweine B, Forestier C. Anti-biofilm activity as a health issue. Front Microbiol 2016;7:592. doi:10.3389/fmicb.2016.00592.

[4] McDonnell G, Russell AD. Antiseptics and disinfectants: activity, action, and resistance. Clin Microbiol Rev 1999;12:147-79.

[5] Alves D, Olívia Pereira M. Mini-review: Antimicrobial peptides and enzymes as promising candidates to functionalize biomaterial surfaces. Biofouling 2014;30:483-99. doi:10.1080/08927014.2014.889120.

[6] Fischbach MA. Combination therapies for combating antimicrobial resistance. Curr Opin Microbiol 2011;14:519-23. doi:10.1016/j.mib.2011.08.003.

[7] Kristensen JB, Meyer RL, Laursen BS, Shipovskov S, Besenbacher F, Poulsen CH. Antifouling enzymes and the biochemistry of marine settlement. Biotechnol Adv 2008;26:471-81. doi:10.1016/j.biotechadv.2008.05.005.

[8] Boles BR, Horswill AR. Agr-mediated dispersal of Staphylococcus aureus biofilms. PLoS Pathog 2008;4:e1000052. doi:10.1371/journal.ppat.1000052.

[9] Banar M, Emaneini M, Satarzadeh M, Abdellahi N, Beigverdi R, van Leeuwen WB, et al. Evaluation of mannosidase and trypsin enzymes effects on biofilm production of Pseudomonas aeruginosa isolated from burn wound infections. PLoS One 2016;11:e0164622. doi:10.1371/journal.pone.0164622.

[10] Selan L, Papa R, Tilotta M, Vrenna G, Carpentieri A, Amoresano A, et al. Serratiopeptidase: a well-known metalloprotease with a new non-proteolytic activity against S. aureus biofilm. BMC Microbiol 2015;15:207. doi:10.1186| s12866-015-0548-8.

[11] Kumar JK. Lysostaphin: an antistaphylococcal agent. Appl Microbiol Biotechnol 2008;80:555-61. doi:10.1007/s00253-008-1579-y.

[12] Chipman DM, Sharon N. Mechanism of lysozyme action. Science 1969;165:454-65. doi:10.1126/science.165.3892.454.

[13] Ramsey DM, Wozniak DJ. Understanding the control of Pseudomonas aeruginosa alginate synthesis and the prospects for management of chronic infections in cystic fibrosis. Mol Microbiol 2005;56:309-22. doi:10.1111/j.1365-2958.2005. 04552.x.

[14] Kaplan JB, Ragunath C, Ramasubbu N, Fine DH. Detachment of Actinobacillus actinomycetemcomitans biofilm cells by an endogenous $\beta$-hexosaminidase activity. J Bacteriol 2003;185:4693-8. doi:10.1128/JB.185.16.4693-4698.2003.

[15] Wang X, Preston JF, Romeo T. The pgaABCD locus of Escherichia coli promotes the synthesis of a polysaccharide adhesin required for biofilm formation. J Bacteriol 2004:186:2724-34. doi:10.1128/jb.186.9.2724-2734.2004.

[16] Okshevsky M, Regina VR, Meyer RL. Extracellular DNA as a target for biofilm control. Curr Opin Biotechnol 2015;33:73-80. doi:10.1016/j.copbio.2014.12.002.

[17] Rutherford ST, Bassler BL. Bacterial quorum sensing: its role in virulence and possibilities for its control. Cold Spring Harb Perspect Med 2012;2 pii: a012427. doi:10.1101/cshperspect.a012427.

[18] Chan K-G, Liu Y-C, Chang C-Y. Inhibiting $N$-acyl-homoserine lactone synthesis and quenching Pseudomonas quinolone quorum sensing to attenuate virulence. Front Microbiol 2015;6:1173. doi:10.3389/fmicb.2015.01173.

[19] Johansen C, Falholt P, Gram L. Enzymatic removal and disinfection of bacterial biofilms. Appl Environ Microbiol 1997;63:3724-8.

[20] Hansen EH, Albertsen L, Schäfer T, Johansen C, Frisvad JC, Molin S, et al. Curvularia haloperoxidase: antimicrobial activity and potential application as a surface disinfectant. Appl Environ Microbiol 2003;69:4611-17. doi:10.1128/AEM 69.8.4611-4617.2003.

[21] Imlay JA. Pathways of oxidative damage. Annu Rev Microbiol 2003;57:395-418 doi:10.1146/annurev.micro.57.030502.090938.

[22] Saiman L. Clinical utility of synergy testing for multidrug-resistant Pseudomonas aeruginosa isolated from patients with cystic fibrosis: 'the motion for' Paediatr Respir Rev 2007;8:249-55. doi:10.1016/j.prrv.2007.04.006.

[23] Jorge P, Pérez-Pérez M, Rodríguez GP, Fdez-Riverola F, Pereira MO, Lourenço A. Construction of antimicrobial peptide-drug combination networks from scientific literature based on a semi-automated curation workflow. Database (Oxford) 2016;2016 pii: baw143. doi:10.1093/database/baw143.

[24] Jorge P, Pérez-Pérez M, Pérez Rodríguez G, Pereira MO, Lourenço A. A network perspective on antimicrobial peptide combination therapies: the potential of colistin, polymyxin B and nisin. Int J Antimicrob Agents 2017;49:668-76. doi:10.1016/j.ijantimicag.2017.02.012.

[25] White RL, Burgess DS, Manduru M, Bosso JA. Comparison of three different in vitro methods of detecting synergy: time-kill, checkerboard, and E test. Antimicrob Agents Chemother 1996;40:1914-18.

[26] Savoia D. New antimicrobial approaches: reuse of old drugs. Curr Drug Targets 2016;17:731-8. doi:10.2174/1389450116666150806124110. 
[27] Fey PD. Modality of bacterial growth presents unique targets: how do we treat biofilm-mediated infections? Curr Opin Microbiol 2010;13:610-15. doi:10. 1016/j.mib.2010.09.007.

[28] Costerton JW, Lewandowski Z, Caldwell DE, Korber DR, Lappin-Scott HM. Microbial biofilms. Annu Rev Microbiol 1995;49:711-45. doi:10.1146/annurev.mi. 49.100195.003431.

[29] Roberts AEL, Kragh KN, Bjarnsholt T, Diggle SP. The limitations of in vitro experimentation in understanding biofilms and chronic infection. J Mol Biol 2015;427:3646-61. doi:10.1016/j.jmb.2015.09.002.

[30] Ragland SA, Criss AK. From bacterial killing to immune modulation: recent insights into the functions of lysozyme. PLoS Pathog 2017;13:e1006512. doi:10. 1371/journal.ppat.1006512.

[31] Bulitta JB, Ly NS, Landersdorfer CB, Wanigaratne NA, Velkov T, Yadav R, et al. Two mechanisms of killing of Pseudomonas aeruginosa by tobramycin assessed at multiple inocula via mechanism-based modeling. Antimicrob Agents Chemother 2015;59:2315-27. doi:10.1128/AAC.04099-14.

[32] ExPASy. ENZYME entry: EC 3.2.1.1. https://enzyme.expasy.org/EC/3.2.1.1 [accessed 30 May 2018].

[33] Fleming D, Chahin L, Rumbaugh K. Glycoside hydrolases degrade polymicrobial bacterial biofilms in wounds. Antimicrob Agents Chemother 2017;61 pii: e01998-16. doi:10.1128/AAC.01998-16.
[34] Ivanova K, Fernandes MM, Francesko A, Mendoza E, Guezguez J, Burnet M, et al. Quorum-quenching and matrix-degrading enzymes in multilayer coatings synergistically prevent bacterial biofilm formation on urinary catheters. ACS Appl Mater Interfaces 2015;7:27066-77. doi:10.1021/acsami.5b09489.

[35] ExPASy. ENZYME entry: EC 3.5.1.14. https://enzyme.expasy.org/EC/3.5.1.14 [accessed 30 May 2018].

[36] Das T, Krom BP, van der Mei HC, Busscher HJ, Sharma PK. DNA-mediated bacterial aggregation is dictated by acid-base interactions. Soft Matter 2011;7:2927. doi:10.1039/c0sm01142h.

[37] Franklin MJ, Nivens DE, Weadge JT, Howell PL. Biosynthesis of the Pseudomonas aeruginosa extracellular polysaccharides, alginate, Pel, and Psl. Front Microbiol 2011;2:167. doi:10.3389/fmicb.2011.00167.

[38] Yu S, Su T, Wu H, Liu S, Wang D, Zhao T, et al. PslG, a self-produced glycosyl hydrolase, triggers biofilm disassembly by disrupting exopolysaccharide matrix. Cell Res 2015;25:1352-67. doi:10.1038/cr.2015.129.

[39] Bastos MD, Coutinho BG, Coelho MLV. Lysostaphin: a staphylococcal bacteriolysin with potential clinical applications. Pharmaceuticals (Basel) 2010;3:1139-61. doi:10.3390/ph3041139.

[40] Haddad Kashani H, Schmelcher M, Sabzalipoor H, Seyed Hosseini E, Moniri R. Recombinant endolysins as potential therapeutics against antibiotic-resistant Staphylococcus aureus: current status of research and novel delivery strategies. Clin Microbiol Rev 2017;31 e00071-17. doi:10.1128/CMR.00071-17. 